\title{
Evaluation of the Anticorrosion and Adsorption Properties of Polyethylene Glycol and Polyvinyl Alcohol for Corrosion of Iron in 1.0 M NaCl Solution
}

\author{
Arej S Al-Gorair ${ }^{1}$, H. Hawsawi ${ }^{2}$, A. Fawzy ${ }^{3}$,M. Sobhi ${ }^{4}$,Ahmed Alharbi ${ }^{3, *}$, R.S. Abdel Hameed ${ }^{5}$, S. Abd \\ El Wanees ${ }^{6}$, M. Abdallah H, $^{3, *}$ \\ ${ }^{1}$ Chem. Depart., College of Sci., Princess Nourah bint Abdulrahman Univ., Riyadh, Saudi Arabia \\ ${ }^{2}$ University College of Alwajh, Alwajh, Tabuk Univ., Tabuk, Saudi Arabia \\ ${ }^{3}$ Chem. Depart. Faculty of Applied Sciences, Umm Al-Qura Univ., Makkah, Saudi Arabia \\ ${ }^{4}$ Chem. Depart. Faculty of Science, Tabuk Univ., Tabuk, Saudi Arabia \\ ${ }^{5}$ Depart. of Basic Sciences, Hail Univ., Hail, 1560 Kingdom of Saudi Arabia \\ ${ }^{6}$ Faculty College of Umluj, Umluj, Tabuk Univ., Tabuk, Saudi Arabia \\ ${ }^{7}$ Chem. Depart., Faculty of Sciences, Benha Univ., Baha, Egypt \\ "E-mail: metwally555@yahoo.com, amaharbi@uqu.edu.sa
}

Received: 9 July 2021 / Accepted: 30 August 2021 / Published: 10 October 2021

The inhibitory vigor of two polymer molecules namely, polyethylene glycol (PEG) and polyvinyl alcohol (PVA) against the corrosion of iron in $1.0 \mathrm{M} \mathrm{NaCl}$ was assessed by chemical and electrochemical technologies. All the computed corrosion parameters from all technologies confirm the inhibitory impact of PEG and PVA compounds. The anticorrosion efficiency increased with the concentration of the polymer molecules to reach $93 \%$ and $86 \%$ at 500-ppm concentration of PEG and PVA, respectively. The potentiodynamic polarization confirms that the two polymer molecules act as mixed inhibitors. The mechanism of the anticorrosion was explicated in terms of the spontaneous adsorption of these molecules on the iron interface according to the negative values of $\Delta G^{\mathrm{o}}$ ads ${ }^{\circ}$ The surface morphology was revealed by SEM images and indicated the building of adsorbed film on the iron surface in the presence of PEG and PVA, which leads to the isolation of iron surface from the corroded $\mathrm{NaCl}$ solution. The activation and the adsorption thermodynamics parameters was determined and explicated.

Keywords: Iron, , Polyethylene glycol, Polyvinyl alcohol, Polarization, Adsorption.

\section{$\underline{\text { FULL TEXT }}$}

(C) 2021 The Authors. Published by ESG (www.electrochemsci.org). This article is an open access article distributed under the terms and conditions of the Creative Commons Attribution license (http://creativecommons.org/licenses/by/4.0/). 